\title{
Freidenberg, Flavia y Suárez-Cao, Julieta (eds.) (2014). Territorio y poder: Nuevos actores y competencia política en los sistemas de partidos multinivel en América Latina. Salamanca: Ediciones Universidad de Salamanca, 386 pp.
}

\author{
JUAN PABLO MILANESE \\ Universidad Icesi
}

\begin{abstract}
"La política latinoamericana ha presentado siempre una muestra variada de competencia partidaria (sistemas hegemónicos, bipartidistas, multipartidistas y atomizados) y de actores políticos relevantes (desde partidos nacidos en el siglo XIX a movimientos sociales que vieron la luz en el albor del siglo XXI, pasando por outsiders de origen cívico y militar). Sin embargo, todas estas características han sido siempre analizadas en su expresión nacional o en relación con fenómenos políticos nacionales" (p. 12).
\end{abstract}

Desde el inicio de la obra las editoras introducen su preocupación por la integración de los distintos niveles para poder comprender cabalmente los procesos de competencia electoral, reconociendo la naturaleza multinivel que esta posee. De este modo, discuten la presunción -expresada explícita o tácitamente por muchos autores- de que la política subnacional representa una función de la nacional y, por lo tanto, existe entre ambas una dinámica homogénea. De hecho, no solo afirman que esto no sucede en aquellos Estados caracterizados por estructuras territoriales de corte federal autonómico, sino también en los unitarios. Rechazan así prejuicios intuitivos sobre la uniformidad en términos de incentivos que cada tipo de arreglo institucional puede producir $\mathrm{y}$, como consecuencia de ello, de los comportamientos y estrategias de las élites partidarias y de los votantes.

Aun esta última afirmación pueda resultar algo más o menos obvio, no lo es necesariamente en el contexto latinoamericano, donde los estudios enfocados en los niveles subnacionales son relativamente jóvenes y lo son aún más aquellos que pretenden comprender la congruencia o incongruencia existente entre ellos. Desde este punto de vista, podemos calificar a Territorio y poder... como una obra de carácter seminal para la región ${ }^{1}$, y augurar que muy probablemente despierte una ola de interés en relación con el tema. Parafraseando a Mercedes García Montero en el capítulo conclusivo del libro, nos encontramos frente a una "(...) obra cuyo aporte no solo contribuye al entendimiento de la dimensión territorial de los sistemas de partidos desde una perspectiva multinivel, sino que abre una agenda de investigación sumamente interesante (p. 377)".

Anteriormente podemos encontrar escasos trabajos que discuten el tema de la congruencia (por ejemplo Gibson y Suárez-Cao, 2010), siendo varios de ellos embriones de la presente publicación (por solo mencionar uno ver Suárez-Cao y Freidenberg, 2010). 
Dentro de este marco, el análisis parte de la relación de las organizaciones partidarias (tradicionales y no tradicionales) y la congruencia de la competencia (alta o baja) entre los distintos niveles. Los resultados muestran la presencia de cuatro combinaciones lógicas que, aunque de forma desigual en lo referido al número de observaciones, revelan la existencia de casos empíricos en casi todas ellas: (1) congruente con predominio tradicional, (2) congruente con predominio no tradicional, (3) incongruente con predominio tradicional $\mathrm{y}$, finalmente, (4) incongruente con predominio no tradicional (única sin referentes empíricos). Pero más allá del valioso ejercicio de clasificación, la investigación también nos muestra otros hallazgos significativos como la visible relación asimétrica que existe entre la congruencia sistémica y el predominio de los partidos tradicionales o la tendencia al aumento de los niveles de incongruencia que precede al declive de estos últimos.

Conclusiones como estas últimas son el resultado de una fértil combinación de enfoques, en la que se complementa un estudio comparado (realizado por Freidenberg y Suárez Cao) que, mediante la utilización de fuzzy sets, logra producir generalizaciones del alcance medio con múltiples estudios de caso (Argentina, Julieta Suárez Cao y Mara Pegoraro; Bolivia, Javier Pérez Mendieta; Chile y Uruguay, Tomáš Došek; Colombia, Margarita Batlle; Costa Rica y Nicaragua, María José Cascante; Ecuador, Flavia Freidenberg; Perú, Margarita Batlle y Jennifer Cyr, y Venezuela, Jennifer Cyr e Iñaki Sagarzazu). Estos últimos consienten un mayor grado de profundización y permiten reconocer las singularidades de cada uno de los casos más allá de las regularidades que los cruzan, cuestión que contribuye notablemente al enriquecimiento del análisis.

Sin embargo, que los autores hayan gozado de libertad para ahondar desde sus análisis las características más significativas de cada país, está lejos de significar la ausencia de una línea de trabajo unificada. De hecho, se ciñeron a una estructura básica que le brinda un alto nivel de coherencia y consistencia al texto, consiguiendo un equilibro normalmente difícil de alcanzar.

Esto nos lleva a realizar otra apreciación relevante como que el libro haya sido resultado de una investigación madura. De hecho, en el mismo capítulo introductorio se hace referencia a un equipo ya constituido en 2009 que trabajó sistemáticamente cobijado por varios proyectos financiados por diferentes organizaciones. Además, más allá de la mención explícita, es evidente que el trabajo ha pasado por numerosos "filtros" desde el punto de vista del debate interno (dentro del equipo de trabajo) y externo (en distintos eventos académicos) $)^{2}$ que han permitido un trabajo riguroso con un resultado final pulido y consistente. ${ }^{3}$

Entre las pocas críticas que pueden realizársele, posiblemente la más significativa sea la ausencia del estudio de casos particularmente relevantes para la región como son los de México y Brasil. Podríamos agregar también algunas cuestiones conceptuales significativas

2 También son enumerados en el texto varios seminarios en los que fueron debatidos borradores de lo que a la postre serían los capítulos de la obra.

3 La madurez también puede ser observada en el amplio número de bases de datos cross-national propias, que contribuyen evidentemente a la calidad de los resultados de investigación evidenciados en el texto final. 
tales como la ausencia de umbrales que nos muestren con relativa precisión en qué momento un partido no tradicional dejaría de ser considerado como tal para incluírselo en el segmento de los tradicionales. Sin embargo, ninguna de estas observaciones opaca la notable calidad del trabajo y la relevancia de los resultados obtenidos.

En resumen, Territorio y poder... constituye un aporte oportuno y relevante para comprender un espacio hasta hoy prácticamente inexplorado de los sistemas de partidos en América Latina. La consistencia del marco analítico, acompañada por el amplio y diverso número de casos junto a la combinación de enfoques, le brinda un nivel de profundidad en el análisis que presagia un esperable impacto en la comunidad académica regional, pudiéndose constituir en un punto de partida ineludible en relación al tema que aborda.

\section{REFERENCIAS}

Gibson, Edward y Julieta Suárez-Cao. 2010. “Federalized Party Systems and Subnational Party Competition: Theory and an Empirical Application to Argentina". Comparative Politics 43 (1): 21-39.

Suárez-Cao, Julieta y Freidenberg, Flavia (2010). Sistemas de partidos multinivel y calidad de la democracia: Una tipología de sistemas de partidos. V Congreso Latinoamericano de Ciencia Política. Asociación Latinoamericana de Ciencia Política, Buenos Aires.

Juan Pablo Milanese es Profesor Asociado del Departamento de Estudios Políticos de la Universidad Icesi, Cali, Colombia. PhD en Ciencias Políticas y Sociales de la Università degli Studi di Bologna y Magister en RRII de la misma universidad. Licenciado en Ciencia Política de la Universidad de Buenos Aires. E-mail: jmilanese@icesi.edu.co 
